\title{
AÇÕES ESTRATÉGICAS PARA A BASE DA PIRÂMIDE NO SETOR IMOBILIÁRIO
}

\section{RESUMO}

Este artigo tem como objetivo analisar as características das ações estratégicas utilizadas no setor imobiliário para o atendimento à população na base da pirâmide (BoP). Especificamente, objetiva-se descrever os elementos-chave da infraestrutura comercial e identificar as estratégias empreendidas para esse segmento no setor imobiliário. A estratégia de pesquisa adotada foi de estudo de casos múltiplos em três empresas: construtora, imobiliária e correspondente bancário. As evidências constataram que a infraestrutura comercial do setor imobiliário da $\mathrm{BoP}$ apresenta aspectos semelhantes aos encontrados nas principais referências sobre o tema. As ações estratégicas estão relacionadas ao auxílio das pessoas na BoP na aquisição de um imóvel, sendo as principais: avaliação de risco e aprovação de crédito simplificado, orientação e assessoria gerencial, uso de internet e aproveitamento de política pública. Ainda, observou-se que o Governo, sendo o principal agente externo, tem uma importante participação para a viabilidade de negócios do setor imobiliário voltados para a BoP. Conclui-se que os resultados da pesquisa avançam na identificação e compreensão das estratégias adotadas por empresas para o atendimento à população da BoP no setor imobiliário.

Palavras-chave: Estratégia; Base da Pirâmide; Setor Imobiliário.

\section{STRATEGIC ACTIONS FOR THE BOTTOM OF THE PYRAMID IN THE HOUSING SECTOR}

\section{ABSTRACT}

This article aims to analyze the characteristics of the strategic actions adopted in the housing sector in order to assist the population ranked in the Bottom of the Pyramid (BoP) market. Specifically, it aims to describe the key elements of the BoP's commercial infrastructure and to identify the strategies adopted to attend the housing sector. The strategy used in this research was the multiple case study conducted at three firms: construction company, real state agency and banking correspondent. The evidences showed that the commercial infrastructure of the housing sector in the BoP market has similar aspects to the ones found in the main references about the theme. The strategic actions are concerned to encouraging people from the BoP market to buy their property, and the main ones are the following: risk assessment and simplified credit approval, management consulting, use of the internet and the utilization of public policy. In addition, it was observed that the Government, as it is the main external agent, plays an important part in the viability of the housing sector business in the BoP market. This study's results advance towards identifying and understanding of the strategies adopted to attend the housing sector.

Keywords: Strategy; Bottom of the Pyramid; Housing Sector. 


\section{ACCIONES ESTRATÉGICAS PARA LA BASE DE LA PIRÁMIDE EN EL SECTOR INMOBILIARIO}

\section{RESUMEN}

Este artículo tiene como objetivo analizar las características de las acciones estratégicas utilizadas en el sector inmobiliario para la atención a la población en la base de la pirámide (BoP). Específicamente, se pretende describir los elementos clave de la infraestructura comercial e identificar las estrategias emprendidas para ese segmento en el sector inmobiliario. La estrategia de investigación adoptada fue de estudio de casos múltiples en tres empresas: constructora, inmobiliaria y corresponsal bancaria. Las evidencias constataron que la infraestructura comercial del sector inmobiliario de BoP presenta aspectos semejantes a los encontrados en las principales referencias sobre el tema. Las acciones estratégicas están relacionadas con el auxilio de las personas en BoP en la adquisición de un inmueble, siendo las principales: evaluación de riesgo y aprobación de crédito simplificado, orientación y asesoría gerencial, uso de internet y aprovechamiento de política pública. Además, se observó que el Gobierno, siendo el principal agente externo, tiene una importante participación para la viabilidad de negocios del sector inmobiliario dirigidos a BoP. Se concluye que los resultados de la investigación avanzan en la identificación y comprensión de las estrategias adoptadas por las empresas para atender a la población de BoP en el sector inmobiliario.

Palabras clave: Estrategia; Base de la Pirámide; Sector Inmobiliario.

\footnotetext{
${ }^{1}$ Mestre em Gestão nas Organizações Aprendentes pela Universidade Federal da Paraíba - UFPB. Brasil. E-mail: anderson.brmail@gmail.com

$\frac{2}{2}$ Doutor em Administração pela Universidade Federal de Pernambuco - UFPE. Professor do Departamento de Administração, do Programa de Pós-Graduação em Administração (PPGA) e do Programa de Pós-Graduação em Gestão nas Organizações Aprendentes (PPGOA) da Universidade Federal da Paraíba - UFPB. Brasil. E-mail: agcmachado@gmail.com
} 


\section{INTRODUÇÃO}

No Brasil, nos últimos anos, apesar dos avanços em prol da diminuição da desigualdade social, a dificuldade de acesso a bens e serviços para a população pertencente à base da pirâmide $(\mathrm{BoP})$ tem persistido, em particular no que diz respeito à habitação, em que existe um déficit de aproximadamente seis milhões de moradias (Fundação João Pinheiro, 2016; Ramos \& Noia, 2016). Para atenuar esse problema e estimular investimentos no setor imobiliário, o Governo Federal lançou, em 2009, o Programa Minha Casa Minha Vida [PMCMV], que até 2015 tinha entregado mais de dois milhões de residências nas diferentes regiões do país (Brasil, 2016).

A população da BoP não corresponde apenas aos que vivem em extrema pobreza, mas também à classe média emergente (Nogami \& Pacagnan, 2011; Prahalad, 2010; Wright \& Spers, 2011). Para Arnold e Valentin (2013), uma pessoa que tem uma renda de até U\$ 9,05 por dia pode ser considerada da BoP, o que equivale a, aproximadamente, $\mathrm{R} \$ 950,00$ por mês. Nesta perspectiva, segundo dados do Censo Demográfico de 2010 (Instituto Brasileiro de Geografia e Estatística [IBGE], 2013) há no Brasil, em média, 3,3 pessoas em cada domicílio, de modo que a renda familiar mensal da BoP pode chegar a, aproximadamente, $\mathrm{R} \$ 2.850,00$.

Apesar de a renda das famílias da BoP ser baixa, diversas empresas do setor imobiliário têm enxergado uma grande oportunidade de crescimento no atendimento a essa parcela da população por meio do PMCMV. Nesse contexto, embora o Programa atenda a famílias pertencentes a quatro faixas de renda familiar (1- até R\$ $1.800,00 ; 1,5$ - entre R\$ $1.800,00$ e R\$ 2.600,00; 2- entre 2.600,00 e R\$ 4.000,00; e 3- entre $\mathrm{R} \$ 4.000,00$ e R\$ 9.000,00) (Caixa Econômica Federal, 2017), a Faixa 1 corresponde a imóveis destinados a famílias cadastradas junto à assistência social de um município, sendo selecionadas por meio dos critérios elencados pelo Ministério das Cidades (2016). Apenas a partir da Faixa 1,5 tem-se a autonomia de escolher seu imóvel, comprando diretamente a uma construtora (Melo, 2016). Dessa forma, para fins deste estudo, serão contempladas somente empresas do setor imobiliário que atendam a pessoas da BoP com renda na Faixa 1,5 do PMCMV.

Para atender ao mercado da BoP, faz-se necessário que as empresas tenham estratégias específicas, além de uma infraestrutura comercial adequada, com vistas a superar as dificuldades encontradas (Barki, Botelho, \& Parente, 2013; Prahalad \& Hart, 2002; Ramos \& Noia, 2016; Rocha \& Silva, 2008). Não obstante haja trabalhos que descrevam políticas e ações empresariais voltadas para o atendimento ao público de baixa renda no setor imobiliário (Medeiros, 2007; Virgilio, 2010; Luz,
2011; Guedes, De Araújo, \& Ornellas, 2012; Costa, 2013; Rodrigues, Rojo, \& Bertolini, 2013; Schreiber, 2013), percebe-se a ausência de estudos que contemplem não apenas as estratégias de diversos elos de atendimento (construtora, imobiliária e correspondente bancário) em conjunto com a percepção dos clientes finais, mas também os principais elementos da sua infraestrutura comercial.

Diante do exposto, o problema de pesquisa foi assim sintetizado: quais as características das ações estratégicas adotadas por empresas do setor imobiliário para atender à população na base da pirâmide $(\mathrm{BoP})$ ? Para responder a essa questão, o objetivo deste artigo é analisar as características das ações estratégicas utilizadas no setor imobiliário para o atendimento à população na BoP. Especificamente, buscou-se descrever os elementos-chave da infraestrutura comercial e identificar as estratégias empreendidas para a BoP no setor imobiliário.

Este estudo se diferencia dos demais na medida em que avança na compreensão da integração entre as ações estratégicas adotadas por empresas localizadas em diferentes estágios do processo de atendimento aos consumidores na BoP no setor imobiliário, incluindo a percepção desses últimos a respeito dos serviços prestados. Além disso, analisa empiricamente as proposições de Prahalad e Hart (2002) quanto aos diferentes elementos que compõem a infraestrutura comercial para a BoP.

Após essa seção introdutória, são apresentadas, na próxima seção, estratégias e aspectos relacionados ao setor imobiliário brasileiro voltado para a base da pirâmide. $\quad \mathrm{Na}$ terceira seção, abordam-se os procedimentos metodológicos e, em seguida, são apresentados e discutidos os resultados. Por fim, são empreendidas as conclusões e sugestões para estudos futuros.

\section{FUNDAMENTAÇÃO TEÓRICA}

Esta seção apresenta aspectos relacionados ao mercado da base da pirâmide, sua infraestrutura comercial e estratégias desenvolvidas para atuação das empresas nesse mercado. Em seguida, discutem-se aspectos do setor imobiliário no Brasil, bem como os principais agentes que atuam no setor.

\subsection{Infraestrutura e Estratégias para a Base da Pirâmide}

Empresas que intencionem servir ao mercado da BoP devem observar algumas condições relativas aos bens e serviços que serão ofertados, tais como: se eles estão relacionados às necessidades básicas das pessoas deste mercado; se só a comunicação de marketing da empresa é suficiente para a sua divulgação ou se será necessário também fazer um 
trabalho informativo e educativo; se são desenvolvidos especificamente para o atendimento a este mercado; e se trarão algum benefício para a vida das pessoas (Jaiswal, 2008).

Nesse contexto, Prahalad e Hart (2002) propõem uma infraestrutura comercial específica para atender à base da pirâmide composta por quatro elementos inter-relacionados: criar poder de compra para que as pessoas deste mercado tenham a possibilidade de adquirir bens e serviços, por meio da disponibilização de crédito, por exemplo; conscientizar e educar os consumidores em prol de um consumo responsável, mediante educação financeira; implementar soluções locais para que os bens e serviços estejam adequados para os consumidores deste mercado, proporcionando às pessoas itens que gerem benefícios econômicos e sociais; e desenvolver um amplo meio de distribuição para facilitar o acesso das pessoas aos bens e serviços.

Os elementos-chave da infraestrutura sugeridos pelos citados autores foram analisados, recentemente, sob a perspectiva de uma política pública de concessão de crédito a microempreendedores de um município do estado da Paraíba (Programa Empreender Bananeiras) (Moura, Machado, \& Bispo, 2015), concluindo-se que o Programa atua como um fomentador da infraestrutura comercial voltada para a BoP.

Além disso, propõem-se quatro princípios estratégicos para desenvolver bens e serviços inovadores para a BoP: percepção de valor, percepção de qualidade, sustentabilidade e rentabilidade (Prahalad \& Hart, 2002). Passos (2013), por sua vez, a partir da revisão da literatura sobre o tema, seleciona treze dimensões estratégicas associadas ao consumo na baixa renda, dentre as quais se destacam a internet e as redes sociais como ferramentas para alcance e maior interação entre as pessoas. Estratégias empresariais que adotam a rede virtual para se comunicar com o público de baixa renda estão alinhadas com resultados de pesquisas que demonstram que $72 \%$ da população brasileira da classe $\mathrm{C}$ utilizam regulamente redes sociais, enquanto nas classes $\mathrm{D}$ e $\mathrm{E}$ este número atinge 69\% (MACIEL, 2013).

Sob a perspectiva brasileira, Zilber e Silva (2010) chamam a atenção para o fato de que, em geral, as empresas têm apenas ampliado a escala de consumo, por meio de posicionamento estratégico, aplicando a diminuição do preço, o fracionamento e a redução das embalagens em seus produtos, não desenvolvendo itens diferenciados para o atendimento ao mercado da BoP. Entretanto, resultados de pesquisas têm ido de encontro a esse entendimento, na medida em que destacam estratégias (Filardi \& Fishmann, 2015) e inovações (Oliveira \& Machado, 2016) específicas para a BoP no contexto nacional, desenvolvidas em diferentes setores, que têm alcançado significativos resultados. Filardi e Fishmann (2015), por sua vez, sintetizaram algumas das principais estratégias relacionadas à $\mathrm{BoP}$, resultando em cinquenta tipos, agrupados nas seguintes categorias: pessoas, bens e serviços, cadeia produtiva, modelo de negócio e estratégias emergentes.

Por outro lado, promover apenas o consumo de bens e serviços para as pessoas da BoP não garante que haja grandes mudanças na sua vida econômica (Karnani, 2007; Landrum, 2007). Uma possibilidade para tanto seria colocá-las dentro do processo produtivo para que haja a geração e o aumento da renda, ou seja, os bens e serviços que são consumidos devem ser produzidos pelas pessoas deste mercado, para que os recursos gerados possam circular dentro da própria região (Hemais, Casotti, \& Rocha, 2013; Karnani, 2009; London, 2007). Assim, não basta que as empresas simplesmente reduzam os preços de seus bens e serviços para atender às pessoas da $\mathrm{BoP}$, mas também implementem novos modelos de negócios, por meio de parcerias locais que não apenas levem as pessoas a consumir, mas gerem desenvolvimento econômico e social (Simanis \& Hart, 2008).

Para a definição de quais e como as estratégias podem ser utilizadas para atender ao mercado da BoP, as empresas devem fazer uma análise das características do mercado e de fatores ligados ao comportamento das pessoas (Parente, Limeira, \& Barki, 2009). Nesse sentido, a próxima seção abordará aspectos relacionados ao setor imobiliário brasileiro voltado para a BoP.

\subsection{Setor Imobiliário Brasileiro para a base da Pirâmide}

Nas duas últimas décadas, com exceção dos dois últimos anos, a condição social e econômica da população brasileira vem gradativamente melhorando, resultando em que pessoas da BoP tenham conseguido ascender social e economicamente (Yamashita \& Rego, 2009). Entretanto, apesar da real diminuição da pobreza e da desigualdade social no país, o déficit habitacional, que era de 6.941 milhões de moradias em 2010 diminuiu para 6.198 milhões de moradias em 2014, representando ainda um grave problema a ser resolvido (Federação das Indústrias do Estado de São Paulo [FIESP], 2016).

O cálculo do déficit habitacional não considera apenas a falta de um imóvel por uma família, mas também a existência de moradias em péssimas condições, que compõem as moradias rústicas e improvisadas; as moradias em coabitação familiar, que têm como composição os cômodos alugados, cedidos e próprios, além de famílias conviventes secundárias com intenção de constituir domicílio exclusivo; moradias em ônus excessivo com aluguel urbano e em adensamento excessivo de domicílios alugados (FJP, 2016).

Uma das formas para combater o déficit habitacional é através das políticas públicas, que representam as ações do Estado na implementação de projetos de governo, mediante programas que visem 
atender demandas específicas da sociedade (Hofling, 2001). Assim, no Brasil, o Governo Federal tem procurado atuar por meio do Programa Minha Casa Minha Vida (PMCMV). Gerido pelo Ministério das Cidades e operacionalizado pela Caixa Econômica Federal (CEF), esse Programa visa atender, principalmente, às famílias da $\mathrm{BoP}$ cuja renda é insuficiente para a aquisição de um imóvel (Medeiros, 2007; Virgilio, 2010) e tem como metas a diminuição do déficit habitacional no país e o aquecimento da economia através das empresas do setor imobiliário (Hirata, 2009). Entre 2010 e 2014, o PMCMV conseguiu uma diminuição de $2,8 \%$ do déficit habitacional na região nordeste do país (Brasil, 2016).

A atuação do governo tem se dado principalmente através do repasse de recursos financeiros, com a finalidade de subsidiar parte do valor do imóvel. Esses subsídios são advindos do Governo Federal, destinados exclusivamente para programas ligados à habitação, e, embora sejam considerados créditos sem retorno para os cofres públicos, muitos impostos e taxas são arrecadados antes, durante e após a construção de um imóvel (Gonçalves Junior, Dutra, Lopes, \& Rodrigues, 2014).

Os agentes financeiros, representados diretamente pelos bancos autorizados pelo PMCMV, entre eles a CEF e o Banco do Brasil (BB), ou indiretamente pelos correspondentes imobiliários, atuam na disponibilização do financiamento dos imóveis. Ademais, diversas empresas do setor imobiliário, como construtoras, incorporadoras e imobiliárias, a partir do PMCMV, procuraram atuar com o intuito de oferecer imóveis direcionados às pessoas da BoP. Contudo, essas empresas são sensíveis à demanda, à facilidade de crédito e aos incentivos do governo e, assim, encontram muitas dificuldades relacionadas ao trâmite burocrático, tais como fatores ligados à aprovação e liberação da construção e financiamento imobiliário. Além disso, a baixa escolaridade dos trabalhadores prejudica o uso de novas tecnologias que poderiam acelerar o processo de construção e, assim, diminuir o preço final do imóvel (Castelo \& Dias, 2013; Luz, 2011).

Ademais, Araújo e Diniz (2014) realizam algumas críticas em relação à estrutura e ao funcionamento do PMCMV, dentre as quais podem-se destacar: o procedimento burocrático para acesso das pessoas da BoP ao PMCMV; o não atendimento específico às necessidades das pessoas da $\mathrm{BoP}$, ou seja, os projetos dos imóveis são padronizados, independentemente da necessidade; a baixa qualidade dos imóveis, algumas vezes apresentando diversas falhas com pouco tempo de construção. Outra crítica, dos mesmos autores, refere-se aos locais onde são construídos os imóveis para o PMCMV: geralmente, são mais distantes dos centros urbanos, sendo áreas de menor valor imobiliário, tornando-se desinteressante para as camadas com maior poder aquisitivo, além disso, esses locais são menos beneficiados com infraestruturas e serviços.

\section{PROCEDIMENTOS METODOLÓGICOS}

A pesquisa foi descritiva, qualitativa e adotou a estratégia de estudo de casos múltiplos. Para selecionar casos que têm como propósito atender aos consumidores da BoP, inicialmente, foram realizadas buscas em sites de empresas que pertencem à cadeia do setor imobiliário da cidade de João Pessoa, capital do estado da Paraíba, isto é, construtoras, imobiliárias e correspondentes bancários. Assim, para as construtoras, foram pesquisadas informações no Conselho Regional de Engenharia e Arquitetura (CREA/PB) e no Sindicato da Indústria da Construção Civil (SINDUSCON/JP); no caso das imobiliárias, pesquisou-se no Conselho Regional de Corretores de Imóveis (CRECI/PB) e no Sindicato dos Corretores de Imóveis (SINDIMÓVEIS/PB); e, para os correspondentes bancários, a $\mathrm{CEF}$ foi pesquisada. Como resultado, sete construtoras, onze imobiliárias e nove correspondentes bancários foram préselecionados. Logo depois, foram realizados contatos telefônicos com a finalidade de confirmar a atuação das empresas no mercado da BoP e sua disponibilidade para participação da pesquisa. Finalizados os contatos, apenas uma empresa representante de cada estágio da cadeia do setor imobiliário apresentou disponibilidade para participar da pesquisa.

A seleção de sujeitos, em cada empresa selecionada, procurou priorizar pessoas que tinham familiaridade com o tema da pesquisa, que estavam ligadas a cargos de gestão e que tinham, principalmente, relação direta com o planejamento estratégico da empresa. Dessa forma, na construtora, foram entrevistadas tanto a gestora administrativa quanto a de marketing; na imobiliária, o gestor administrativo e o gestor de negócios imobiliários; e, por fim, no correspondente bancário, foram entrevistadas a gestora comercial e a analista de processos imobiliários. $\mathrm{O}$ estudo também buscou verificar a percepção dos consumidores da BoP com relação às ações estratégicas das empresas envolvidas. Para isso, selecionaram-se, adotando um critério de conveniência, cinco pessoas que adquiriram seus respectivos imóveis por meio do PMCMV, tendo em vista que as empresas que atuam no segmento dos imóveis para BoP utilizam o referido Programa. Portanto, no total, onze sujeitos foram entrevistados. Todos os nomes, tanto das empresas quanto das pessoas entrevistadas, foram preservados para manter o sigilo exigido pelos participantes.

Os dados foram coletados entre os meses de agosto e outubro de 2016 e novembro e dezembro de 2017, mediante entrevistas semiestruturadas, observações diretas sistemáticas e análise de documentos. Para as entrevistas, foram utilizados dois 
roteiros distintos, sendo um para os gestores das organizações envolvidas e outro para os consumidores. Para os gestores, o roteiro de entrevista foi dividido em duas seções. Na primeira seção, um conjunto de questões teve o intuito de colher dados referentes ao perfil da empresa e do entrevistado, bem como as principais vantagens e desvantagens de atuar no mercado da BoP. A segunda seção, composta por 23 questões, objetivou esclarecer os elementos-chave da infraestrutura comercial, as estratégias empreendidas para a base da pirâmide e o papel dos agentes externos nos negócios. O roteiro adotado para entrevistar os consumidores, por seu turno, foi composto por um conjunto de questões iniciais que buscaram compreender a profissão e a renda familiar do respondente, a localização, a data de compra e o tamanho do imóvel adquirido. Em seguida, 13 questões tiveram o propósito de averiguar o processo de compra, incluindo aspectos associados ao atendimento, às condições de aquisição, ao crédito disponibilizado e aos fatores que influenciaram o processo decisório. Todas as entrevistas foram gravadas e, posteriormente, transcritas.

As observações também adotaram um roteiro que incluiu elementos que envolviam a localização da empresa e sua acessibilidade aos consumidores, a organização do ambiente interno, o horário e a flexibilidade no atendimento. Os documentos analisados, por sua vez, disseram respeito, principalmente, a materiais publicitários disponibilizados nos websites das empresas e informações dispostas nas redes sociais.

Para a análise dos dados, utilizou-se a técnica de análise de conteúdo, e essa foi composta por três etapas (Bardin, 1977). Na primeira etapa, foram feitas a transcrição e a leitura a fim de ter visão geral do material coletado. Em seguida, os dados foram agrupados nas seguintes categorias: (1) infraestrutura comercial; (2) estratégias; e (3) atuação de agentes externos. Nessa mesma etapa, as duas primeiras categorias foram analisadas a partir das seguintes dimensões: dimensão 1 - poder de compra, aspirações, soluções locais, e acesso; dimensão 2 - produto/serviço, cadeia produtiva, modelo de negócio, estratégias emergentes, e ferramentas da web. Por fim, na terceira etapa, foi executada uma análise individual de cada empresa e, posteriormente, de forma transversal, verificaram-se semelhanças e diferenças entre os casos por meio de uma análise cruzada dos dados.

\section{APRESENTAÇÃO E DISCUSSÃO DOS RESULTADOS}

Nesta seção são apresentadas as análises individuais dos dados de certos atores da cadeia do setor imobiliário selecionados para esta pesquisa (construtora, imobiliária e correspondente bancário), bem como a percepção dos clientes que adquiriram imóveis pelo PMCMV. Objetiva-se, pois, compreender como os elementos-chave da infraestrutura comercial para a base da pirâmide propostos por Prahalad e Hart (2002) estão presentes e são desenvolvidos pelos atores citados, além de caracterizar as estratégias empreendidas para o atendimento ao público de baixa renda.

\subsection{Construtora}

A empresa atua no ramo de construção civil desde o ano de 1998, contudo, só a partir de 2010 entrou no mercado de construção de imóveis para atendimento específico às pessoas da BoP. Atualmente, a construtora conta com um quadro de 243 colaboradores. Para o desenvolvimento do negócio na BoP, as evidências permitem afirmar que a construtora implementa aspectos semelhantes àqueles sugeridos por Prahalad e Hart (2002).

Nesse sentido, no aspecto de criar poder de compra, tem-se procurado facilitar o pagamento do valor de entrada do imóvel por meio da concessão de financiamento direto relativo ao saldo não financiado pelo banco. Dessa forma, em consonância com Prahalad e Hart (2002) e Karnani (2007), por meio da disponibilização de crédito, a empresa cria condições financeiras para que pessoas de baixa renda tenham a possibilidade de adquirir um imóvel. Para isso, a construtora procura verificar a capacidade de pagamento do cliente, o que se dá por meio do cruzamento de dados financeiros e econômicos, de entrevista e da análise de comprovantes de renda. A entrevista com o potencial cliente, embora seja a fase de cunho mais subjetivo, é importante para mais bem compreender a sua disponibilidade financeira e elaborar um cronograma de pagamentos que será oficializado em contrato, conforme relatado pela entrevistada:

Após a aprovação do financiamento bancário, o cliente vem para a construtora e nós dividimos o resto (...) digamos que o valor da parcela, do financiamento bancário, ficou no valor de $\mathrm{R} \$ 500,00$, aí pergunto para a pessoa quanto ela pode encaixar mais para pagar por mês, aí digamos ela nos diga um valor de $\mathrm{R} \$ 1.000,00$ que pode pagar por mês, aí já faço a parcela de $\mathrm{R} \$ 500,00$ para ela pagar a construtora, aí pergunto sobre o décimo e as férias, aí ela começa a pensar: devo ter um valor por volta de $\mathrm{R} \$ 3.000,00$, aí falo para ela me repassar o valor como intercalada, aí formalizamos tudo isso no contrato.

As estratégias associadas à geração de poder de compra estão relacionadas à avaliação de risco, à aprovação de crédito simplificado, à redução de garantias para crédito e da burocracia, e à flexibilização de regras para clientes da BoP, conforme apresentam Filardi e Fischmann (2015). 
A conscientização e a educação para o consumo responsável, conforme sugerido por Prahalad e Hart (2002), podem ser verificadas mediante o planejamento financeiro reportado ao cliente após a análise de sua situação financeira e econômica. Sendo assim, a construtora também utiliza, em alinhamento com Filardi e Fischmann (2015), a estratégia de orientação e assessoria gerencial. Esse fato foi verificado também no website da construtora, no qual existe uma série de orientações para a compra do primeiro imóvel. A orientação está em levar o cliente a visualizar a responsabilidade para com o pagamento de um bem que é de grande importância para ele, pois, em alguns casos, como destaca Karnani (2009), caso ele não tenha esse compromisso, gasta a sua renda com itens supérfluos e, dessa forma, acaba não acumulando capital suficiente para a quitação do imóvel.

Para que os imóveis estejam adequados aos consumidores deste mercado, a construtora procura fazer um estudo, que consiste, primeiramente, em verificar se a área está enquadrada dentro dos requisitos para o PMCMV. Além disso, conforme apresentam Prahalad e Hart (2002), Wright e Spears (2011), Prahalad (2010) e Karnani (2009), verifica-se que tipo de empreendimento pode se encaixar no perfil das pessoas da BoP, tentando sempre agregar o maior número de itens que gerem valor ao imóvel, como, por exemplo, uma boa área de lazer, sem, contudo, aumentar demasiadamente os custos da obra, de forma que o valor do imóvel possa estar até o limite máximo das faixas permitidas pelo PMCMV. Como forma de divulgação dos empreendimentos, a construtora procura utilizar os meios de mídia digital, como a televisão, além da internet (redes sociais). Assim, este quesito está ligado às estratégias de utilização de ferramentas da internet, como descrito por Passos (2013).

Além disso, para ter um amplo meio de distribuição e facilitar o acesso das pessoas aos imóveis, como descrito por Prahalad e Hart (2002) e Wright e Spears (2011), a construtora faz parcerias com imobiliárias, correspondentes bancários e governo (municipal, estadual ou federal). Nos dois primeiros casos, as estratégias utilizadas estão relacionadas às parcerias com outras empresas e às ações para atrair novos clientes, bem como à otimização da cadeia produtiva. No terceiro caso, a construtora utiliza as estratégias de estabelecimento de parcerias com o governo e de aproveitamento de políticas públicas para viabilizar a construção de empreendimentos em locais com pouca infraestrutura (de modo a não onerar o valor final do imóvel), conforme apresentam Filardi e Fischmann (2015).

Uma das formas de estabelecer parcerias entre a construtora e o governo consiste na compensação dos tributos, isto é, a empresa apresenta o projeto ao órgão competente que, por sua vez, verifica e autoriza a própria construtora a realizar a obra de infraestrutura no local, como explica uma das entrevistadas: "A gente entra em parceria com a Prefeitura, através do IPTU Cidadão, a gente faz o levantamento de impostos de quanto seria para calçar uma rua, aí a Prefeitura diz o valor, e ficamos recebendo como crédito tributário".

Para a viabilização financeira, a construtora adota também estratégias de volume com ganho de escala e preço/performance, em alinhamento com Filardi e Fischmann (2015), Prahalad e Hart (2002) e Wright e Spers (2011), além de financiar o imóvel com a obra ainda em andamento, de modo a gerar fluxo de caixa para garantir a segurança do investimento e a velocidade na conclusão do produto, conforme explica uma das gestoras: "Um dos nossos empreendimentos tem 320 apartamentos, aí tivemos que fazer uma estratégia para ele, que foi financiar na planta (...) o cliente compra hoje e já dá entrada hoje no banco para tirar a carta de crédito e a gente fica recebendo, conforme vai construindo (...)".

Uma estratégia também observada no website da construtora e nas redes sociais é a de que ela tem um apartamento decorado para que o cliente possa fazer uma visita e ter uma ideia de como ficará o imóvel após a finalização da obra. Esse fato pode ser relacionado à estratégia de poder testar o produto antes de adquiri-lo, conforme descrito Filardi e Fischmann (2015).

\subsection{Imobiliária}

A imobiliária tem como foco o PMCMV e oferta, aproximadamente, 4000 imóveis em suas seis unidades, das quais quatro delas estão localizadas na região onde se encontra o maior número de imóveis oferecidos às pessoas da BoP da cidade de João Pessoa.

No item que se refere a criar poder de compra, conforme descrevem Prahalad e Hart (2002) e Karnani (2007), a imobiliária tem atuado no sentido de intermediar a negociação de compra do imóvel. A estratégia de otimização da cadeia produtiva, apresentada por Filardi e Fischmann (2015), pôde ser evidenciada na operação do processo de compra do imóvel pelo cliente, na qual a imobiliária, em conjunto com a construtora, busca encontrar a melhor forma para viabilização do crédito, tendo em vista que o processo de financiamento bancário representa uma etapa burocrática, sendo necessário que o cliente tenha um histórico bancário de capacidade de pagamento, como relata o entrevistado:

O banco ficou muito criterioso, então para você encontrar um cliente nessa faixa que nunca deveu, nunca fez acordo, ele está com o nome limpo, sem nenhuma restrição, mas o histórico dele de cliente pagador não é um histórico tão bom, isso faz com que o banco trave algumas coisas (...) então esse é a maior dificuldade, de achar aquele cliente que tenha um bom histórico. 
A exemplo do que já foi relatado sobre a construtora, e em consonância com Prahalad e Hart (2002), Karnani (2009) e Wright e Spers (2011), a empresa busca conscientizar os clientes a respeito da responsabilidade com o financiamento e a necessidade de se ter um controle financeiro da renda familiar. Esse aspecto pode ser relacionado às estratégias de prestar orientação e assessoria gerencial e a de ensinar aos clientes a importância do bem/serviço, conforme descrito por Filardi e Fischmann (2015). Para isso, apresentam-se ao cliente todos os aspectos do financiamento, desde os valores da parcela até as taxas e seguro, para o caso da ocorrência de um imprevisto com relação à pessoa que está adquirindo o imóvel, conforme descreve o entrevistado:

O pessoal deve entender que esse programa habitacional, o Minha Casa Minha Vida, ele não é só a compra de um imóvel, ele é a compra de um imóvel e uma garantia para a família da pessoa. Existe um seguro habitacional que você paga junto com a parcela (...). Esse seguro é pago em todas as parcelas. Então, o que ele garante para você? Em caso de morte, esse imóvel é quitado, então os herdeiros não vão para a rua, nem o banco vai tomar o imóvel; no caso de acidente e a pessoa ficou inválida, esse imóvel, também, é quitado; a pessoa ficou desempregado, aí a pessoa pode acionar o seguro, para que o seguro possa pagar até 18 meses de parcelas para a pessoa.

Além disso, o cliente tem a possibilidade de estar adquirindo um bem que será seu, pagando muitas vezes o valor que estaria pagando numa locação de um imóvel, conforme relato de um dos entrevistados: “(...) compreendemos que o nosso cliente tem a possibilidade de sair do aluguel, adquirindo um imóvel financiado pelas condições do PMCMV, pois o valor da parcela do financiamento fica dentro do valor de mercado da locação de imóvel das mesmas características que o cliente está adquirindo".

Como forma de permitir um atendimento personalizado e facilitar a aquisição dos imóveis, a imobiliária estuda o perfil financeiro de cada cliente em relação à faixa de valores dos produtos disponibilizados pelas construtoras e verifica o valor do subsídio oferecido pelo PMCMV ao cliente, que, somado ao valor do financiamento bancário, irá compor o valor total do imóvel. Evidencia-se, portanto, em alinhamento com Filardi e Fischmann (2015), a adoção de estratégias de aproveitamento de políticas públicas (via financiamento) e de adequação do bem para um determinado consumidor.

Para ampliação do acesso aos produtos, em acordo com Prahalad e Hart (2002) e Wright e Spears (2011), a empresa procura flexibilizar seu atendimento, inclusive funcionando aos finais de semana, em regime de plantão, tendo em vista que o público-alvo desse mercado, em sua maioria, tem seu horário comercial comprometido. Em alguns casos são utilizadas, inclusive, outras estruturas para plantão externo nos locais dos empreendimentos ou em feirões. Estas ações, de acordo com Filardi e Fischmann (2015), estão relacionadas às estratégias baseadas no relacionamento, envolvendo parceiros locais, além de lojas de pequeno porte.

\subsection{Correspondente Bancário}

A empresa começou suas atividades, originalmente, como imobiliária, no ano de 2008, tendo prosseguido para o ramo de correspondente bancário em 2011, devido ao grande crescimento do mercado imobiliário, com o lançamento do PMCMV. Credenciou-se, assim, junto à $\mathrm{CEF}$, dando início às atividades no segmento, o qual constituiu o principal mercado de atuação da empresa.

Um importante elemento da infraestrutura comercial sugerido por Prahalad e Hart (2002), e que se destaca no caso das atividades do correspondente bancário, é a análise do cliente para concessão de crédito, conforme relata, a seguir, uma das entrevistadas. Isso está também relacionado à estratégia de avaliação de risco e aprovação de crédito simplificado, além da redução de burocracia e da flexibilização de regras para clientes das comunidades, conforme apresentam Filardi e Fischmann (2015).

A gente começa recolhendo o máximo de
documentação para poder entrevistar o
cliente, para saber com que ele trabalha, se
ele irá financiar o imóvel sozinho, saber se
ele tem uma renda comprovada ou se ele
trabalha informalmente, aí pegamos toda a
documentação do cliente e vamos analisar
(...). Digamos, o cliente tem uma renda de
contracheque ou uma renda comprovada, no
valor de um salário comercial, $\mathrm{R} \$ 1.038,00$, e
declara que vende produtos e, mensalmente,
ele consegue mais o valor de $\mathrm{R} \$ 800,00$ ou
$\mathrm{R} \$ 900,00$, aí analisamos todas as contas de
consumo, da fatura de cartão de crédito, notas
fiscais das compras dos produtos para
revenda (...) então a gente observa para saber
o quanto o cliente está com a renda
comprometida.

O processo de financiamento imobiliário do PMCMV, por sua vez, pode variar de uma instituição financeira para outra. Isto é, o que pode facilitar a aprovação da carta de crédito do cliente numa instituição pode dificultar em outra, conforme relato de uma das entrevistadas: “(...) no critério de o cliente ter um 'histórico pagador', por exemplo, caso ele tenha uma sobrecarga de contas em uma instituição poderá ser entendido que, apesar de pagar, o cliente está muito comprometido. Entretanto, em outra, poderá ter o entendimento que o cliente tem boa capacidade de pagamento". 
A empresa também orienta o cliente durante a abertura de conta em uma agência bancária para que comece a fazer movimentações financeiras e crie uma reserva econômica, sob a perspectiva da educação do consumidor (Prahalad \& Hart, 2002; Karnani, 2009). Desta forma, o mesmo irá criar um histórico bancário e, quando for feita a análise de crédito, terá maior possibilidade de aprovação, conforme relata a entrevistada:

Se a gente encontra um cliente que está com interesse num imóvel que está ainda em fase de acabamento, com ainda uns dois ou três meses para a construtora concluir esse imóvel, então nesse período a gente vai analisar o que ele tem. Às vezes o cliente diz que vende roupa e não tem nada no nome dele, não tem nota fiscal, não movimenta conta, então a gente sempre o aconselha a abrir e movimentar uma conta, pegar os valores que ele recebe com essa renda informal para começar a movimentar em conta, para que na análise da carta de crédito a gente tenha subsídios, comprovados por ele, para utilização da sua renda.

O correspondente bancário também procura contatar imobiliárias e construtoras para encaminharem seus clientes e, assim, agilizar o processo de financiamento bancário. Todos estes aspectos, conforme asseveram Filardi e Fischmann (2015), estão relacionados às estratégias de orientação e assessoramento, bem como de estabelecimento de parcerias com fornecedores locais. Além disso, como agente externo, o governo representa um grande influenciador deste mercado, considerando que a concessão de crédito para o financiamento pode ser modificada por meio de políticas econômicas.

\subsection{Clientes}

A Cliente 1 adquiriu o imóvel a partir de uma busca realizada, primeiramente, na internet e, a partir disso, ela selecionou os imóveis mais interessantes para seus propósitos. Em seguida, entrou em contato telefônico com a imobiliária ou construtora, obtendo mais informações sobre eles. Contudo, o imóvel adquirido ocorreu a partir da indicação de uma pessoa conhecida, que já morava próxima ao local. Desta forma, o fechamento ocorreu em contato com uma imobiliária, que a partir daí apresentou todo o imóvel e a direcionou para a construtora.

O Cliente 2 adquiriu o imóvel a partir de uma busca, por conta própria, no bairro em que desejava, tendo em vista que tentou, em contato com um corretor de imóveis, localizar algo que estivesse dentro de seu planejamento, mas este não conseguiu que se encaixasse em seu perfil. A Cliente 3, por sua vez, estava à procura de um imóvel para locação. Entretanto, ao passar por um empreendimento em construção, procurou saber mais detalhes de como seria o processo de compra, em um estande de uma imobiliária que estava na frente do empreendimento. Assim, ao analisar as condições propostas pelo corretor de imóveis, fechou o negócio com a construtora.

A cliente 4, por seu turno, adquiriu seu imóvel no início do PMCMV, procurando um bem que se adequasse ao seu orçamento familiar. Assim, ela conseguiu adquirir seu imóvel em um bairro mais afastado do centro da cidade, distante do seu trabalho, contudo dentro do planejado para seu orçamento. $\mathrm{O}$ cliente 5, por fim, tinha como meta adquirir seu imóvel como um investimento financeiro, pois já tinha algum recurso reservado, o que facilitou a aquisição.

Em relação ao acesso ao crédito, primeiro elemento da infraestrutura comercial sugerido por Prahalad e Hart (2002), a Cliente 1 parcelou a entrada do valor do imóvel no cartão de crédito. Já os Clientes 2 e 5 pagaram o valor de entrada de uma única vez, sendo que o Cliente 2 recebeu um desconto no valor acordado. Por fim, as Clientes 3 e 4 optaram pelo parcelamento direto com a construtora do valor de entrada do imóvel.

No aspecto de educação do consumidor, segundo elemento abordado por Prahalad e Hart (2002), os clientes não perceberam que houve, por parte das empresas, orientação com relação ao planejamento financeiro. A Cliente 1 relatou que não houve a preocupação, por parte do vendedor, de avaliar se o valor a ser pago por ela daria para ser incluído no orçamento familiar. Os Clientes 2 e 5, por sua vez, relataram que apenas assinaram o contrato e fizeram o pagamento do valor da entrada e que, a partir daí, tiveram pouco contato com o vendedor do imóvel. A Cliente 3 ficou insatisfeita com a pouca orientação que recebeu sobre o trâmite do processo de compra, pois não sabia que precisaria de um valor em dinheiro para abertura de conta no banco como condição para ser liberado o financiamento bancário. A Cliente 4, apesar de o valor de cada parcela ter ficado adequado para seu orçamento, criticou a falta de clareza quanto às etapas do financiamento do imóvel.

No que diz respeito a construir soluções locais, conforme descrito na infraestrutura comercial apresentada por Prahalad e Hart (2002), os clientes 1, 2,3 e 5 ficaram satisfeitos, pois os imóveis atendiam a suas diversas expectativas, como, por exemplo, serem em locais com infraestrutura adequada e estarem bem localizados. No entanto, a Cliente 4, corroborando certas críticas empreendidas por Araújo e Diniz (2014) a respeito do PMCMV, demonstrou insatisfação em relação à localização de seu imóvel, conforme relata a seguir:

Para me deslocar ao meu trabalho preciso pegar o transporte público, entretanto, uma única empresa, com poucos ônibus, atende ao bairro onde se localiza o imóvel, o que me faz perder bastante tempo para chegar ao 
trabalho. Além disso, no bairro ainda existe pouco comércio, o que leva a ter que me deslocar até o bairro vizinho para adquirir algum produto que necessito.

Já com relação à ampliação dos links de distribuição, com vistas a um melhor acesso às empresas pelas pessoas da BoP, outro elemento da infraestrutura comercial, observou-se que houve fácil acesso às empresas no momento da compra do imóvel, sendo a internet, alinhado ao que foi destacado por Passos (2013), uma das formas mais utilizadas para o alcance dos consumidores da BoP.

Entretanto, conforme observado nas entrevistas, as pessoas que já estavam utilizando os imóveis sentiram certa dificuldade no pós-venda, em particular no que diz respeito à assistência técnica. Embora o cliente tenha uma garantia de cinco anos para a reparação de danos estruturais que surjam no imóvel, há certa dificuldade para que esses reparos possam ser feitos, mesmo dentro do prazo estabelecido.

\section{ANÁLISE CRUZADA DOS CASOS}

Os dados analisados de forma individual na seção anterior são discutidos transversalmente nesta seção de forma a verificar semelhanças e diferenças entre os casos. Nesse sentido, ao se analisar os elementos da infraestrutura comercial para o atendimento ao mercado da BoP, conforme apresentado por Prahalad e Hart (2002), evidenciou-se que são desenvolvidos, na íntegra, tanto pela construtora quanto pela imobiliária, conforme sintetizado no Quadro 1.

\begin{tabular}{|c|c|c|c|}
\hline $\begin{array}{c}\text { Elementos da Infraestrutura Comercial propostos por } \\
\text { Prahalad e Hart (2002) }\end{array}$ & Construtora & Imobiliária & $\begin{array}{l}\text { Correspondente } \\
\text { Bancário }\end{array}$ \\
\hline $\begin{array}{c}\text { Criar poder de compra: acesso ao crédito e geração de } \\
\text { renda. }\end{array}$ & $X$ & $X$ & $X$ \\
\hline $\begin{array}{c}\text { Educar os consumidores em prol de um consumo } \\
\text { responsável }\end{array}$ & $X$ & $X$ & $X$ \\
\hline $\begin{array}{c}\text { Construir soluções locais para que os bens e serviços } \\
\text { estejam adequados para os consumidores. }\end{array}$ & $X$ & $X$ & - \\
\hline $\begin{array}{l}\text { Ampliar os meios de distribuição para facilitar o acesso } \\
\text { das pessoas aos bens e serviços. }\end{array}$ & $\mathrm{X}$ & $\mathrm{X}$ & - \\
\hline
\end{tabular}

Quadro 1 - Infraestrutura comercial dos componentes da cadeia do setor imobiliário Fonte: Elaboração própria (2017).

O correspondente bancário não apresentou dois aspectos da infraestrutura comercial: construir soluções locais para que os bens e serviços estejam adequados aos consumidores do mercado da BoP e ter um amplo meio de distribuição para facilitar o acesso das pessoas aos bens e serviços. Isso se deve ao fato de o correspondente bancário ter a atividade de prestação de serviço vinculada a uma instituição financeira e, dessa forma, o desenvolvimento do seu negócio fica restrito a atender dentro de uma determinada região.

Já em relação aos clientes, estes não perceberam como foram educados para o consumo consciente, não reconhecendo a atuação das empresas nesse quesito. Entretanto, durante a pesquisa, foi evidenciado que todas as empresas estão buscando meios para orientar e assessorar os clientes com relação a um planejamento financeiro. No caso da construtora, por exemplo, foi observado que em seu website existem diversas orientações para um planejamento financeiro de um casal quanto à compra do primeiro imóvel.

Analisando-se as estratégias executadas pelas empresas selecionadas (Quadro 2), e classificadas de acordo com Passos (2013) e Filardi e Fischmann (2015), evidencia-se, em consonância com Simanis e Hart (2008), a carência de ações que envolvam os consumidores da BoP com o propósito de promover o seu desenvolvimento social e econômico, a favor de apenas executar atividades que viabilizem a comercialização de bens e serviços para esse público. 
Ações Estratégicas para a Base da Pirâmide no Setor Imobiliário

\begin{tabular}{|c|c|c|c|c|}
\hline \multicolumn{2}{|r|}{ Estratégias } & Construtora & Imobiliária & $\begin{array}{l}\text { Correspondente } \\
\text { Bancário }\end{array}$ \\
\hline \multirow{5}{*}{ Bens/Serviços } & $\begin{array}{c}\text { Ensino aos clientes sobre a importância } \\
\text { e a utilidade do bem/serviço }\end{array}$ & & $X$ & $\mathrm{X}$ \\
\hline & $\begin{array}{c}\text { Aumentar o volume e gerar ganhos de } \\
\text { escala }\end{array}$ & $X$ & & \\
\hline & Preço/performance & $X$ & & \\
\hline & $\begin{array}{l}\text { Permissão aos clientes para testar antes } \\
\text { de comprar }\end{array}$ & $\mathrm{X}$ & & \\
\hline & $\begin{array}{c}\text { Avaliação de risco e aprovação de } \\
\text { crédito simplificado }\end{array}$ & $\mathrm{X}$ & & $\mathrm{X}$ \\
\hline \multirow[b]{2}{*}{ Cadeia Produtiva } & Otimização da cadeia produtiva & $\mathrm{X}$ & $\mathrm{X}$ & \\
\hline & $\begin{array}{l}\text { Realização de parcerias com } \\
\text { fornecedores locais }\end{array}$ & & & $\mathrm{X}$ \\
\hline \multirow{2}{*}{$\begin{array}{l}\text { Modelo } \\
\text { de negócio }\end{array}$} & Criação de lojas de pequeno porte & & $\mathrm{X}$ & \\
\hline & Redução das garantias para crédito & $\mathrm{X}$ & & \\
\hline \multirow{7}{*}{$\begin{array}{l}\text { Estratégias } \\
\text { emergentes }\end{array}$} & Aproveitamento de política pública & $\mathrm{X}$ & $\mathrm{X}$ & $\mathrm{X}$ \\
\hline & $\begin{array}{l}\text { Divulgação das ações para atrair os } \\
\text { clientes e parceiros }\end{array}$ & $\mathrm{X}$ & & \\
\hline & Estratégia baseada no relacionamento & & $\mathrm{X}$ & \\
\hline & $\begin{array}{l}\text { Realização de parceria com outras } \\
\text { grandes empresas }\end{array}$ & $\mathrm{X}$ & & \\
\hline & $\begin{array}{l}\text { Realização de parceria com governo e } \\
\text { prefeitura }\end{array}$ & $X$ & & \\
\hline & Orientação e assessoria gerencial & $\mathrm{X}$ & $\mathrm{X}$ & $\mathrm{X}$ \\
\hline & $\begin{array}{l}\text { Redução de burocracias e flexibilização } \\
\text { de regras para clientes das comunidades }\end{array}$ & $\mathrm{X}$ & & \\
\hline \multirow{2}{*}{$\begin{array}{l}\text { Ferramentas da } \\
\text { web }\end{array}$} & Adoção da Internet & $\mathrm{X}$ & $\mathrm{X}$ & $\mathrm{X}$ \\
\hline & Utilização de Redes sociais & $\mathrm{X}$ & $\mathrm{X}$ & \\
\hline
\end{tabular}

Quadro 2 - Ações estratégicas do setor imobiliário

Fonte: Elaboração própria (2017).

Nas estratégias relacionadas ao grupo bem/serviço, o item ensinar aos clientes a importância e a utilidade do bem/serviço foi observado na imobiliária e no correspondente bancário. Além disso, o item de avaliação de risco e aprovação de crédito simplificado representa uma estratégia de grande relevância para o segmento, tendo em vista que torna o bem acessível às pessoas da $\mathrm{BoP}$, sendo observado na construtora e no correspondente bancário, como também foi verificado pelos clientes entrevistados no momento da aquisição de seus imóveis. No grupo de estratégias ligadas à cadeia produtiva, a ação mais encontrada foi a de otimização da cadeia produtiva, demonstrando que, para uma melhor performance do desenvolvimento do negócio, a empresa deve se associar a outras, mesmo de segmentos diferentes, contanto que estejam dentro do mesmo setor.

Com relação às estratégias do modelo de negócio, apenas duas ações foram evidenciadas: criação de lojas de pequeno porte (imobiliária) e redução das garantias para crédito (construtora). Dessa forma, as empresas não demonstraram que têm aspectos específicos em seus modelos diretamente voltados para a BoP, mas sim que englobaram este mercado dentro de seu modelo de negócio, como destacado por Zilber e Silva (2010).

No grupo de estratégias emergentes, podem-se destacar duas ações como as mais utilizadas pelos componentes do setor imobiliário. A primeira envolve aproveitar políticas públicas, tendo significativa importância para o desenvolvimento dos negócios voltados para as pessoas da BoP. A segunda refere-se à orientação e assessoria gerencial que as empresas têm buscado realizar durante o processo de compra de um imóvel, embora os resultados dessa estratégia não tenham sido percebidos pelos clientes.

Já as estratégias relacionadas às ferramentas da internet foram evidenciadas em todos os casos pesquisados, ou seja, busca-se aumentar a divulgação dos imóveis por meio da utilização de websites próprios e da exposição de produtos, embora apenas a construtora e a imobiliária estejam utilizando 
ativamente as redes sociais como ação estratégica. Considerando que a adoção de redes sociais está disseminada na maioria dos usuários de internet das classes C, D e E (Maciel, 2013), percebe-se, com exceção do correspondente bancário, o alinhamento entre as ações empresariais empreendidas no meio virtual e o comportamento da população de baixa renda no contexto brasileiro. Dessa forma, entende-se que, apesar de o meio digital nos dias atuais estar mais acessível, o contato pessoal com o cliente ainda tem sido o principal canal para o fechamento de negócios.

O Governo Federal e o Municipal, por sua vez, representam os principais agentes externos, tendo significativos impactos em todos os estágios da cadeia do setor imobiliário, principalmente no que se refere aos recursos financeiros, seja no aspecto de subsídio ou nas normas para concessão de financiamento bancário, conforme destacado por Gonçalves Junior et al. (2014).

Pode-se considerar o Governo Federal como o agente que tem maior impacto em toda a cadeia do setor imobiliário devido ao seu papel regulamentador do PMCMV, em que qualquer mudança nas normas pode afetar diretamente o desenvolvimento do negócio das empresas do setor imobiliário que atendem às pessoas da BoP. Por exemplo, se houver qualquer alteração nas normas com relação à liberação do subsídio, isso poderá afetar diretamente a venda de um imóvel para uma pessoa da BoP, tendo em vista que o desconto concedido no valor do imóvel é significativo para o fechamento do negócio. Já no âmbito municipal, o Governo tem propiciado incentivos por meio do estabelecimento de parcerias com as construtoras para a melhoria da infraestrutura nos locais dos empreendimentos.

\section{CONCLUSÕES}

Por meio das evidências, foi observado que a infraestrutura comercial desenvolvida por empresas pertencentes à cadeia do setor imobiliário voltado para a BoP tem elementos semelhantes aos sugeridos por Prahalad e Hart (2002). No que diz respeito à necessidade de criar poder de compra, por exemplo, há alternativas para o pagamento do valor da entrada do imóvel, aliadas à educação financeira, para que o cliente se mantenha adimplente com os saldos a pagar. Além disso, as empresas têm construído imóveis principalmente em regiões onde está concentrado o maior número de pessoas da $\mathrm{BoP}$, levando soluções locais alinhadas a um sistema de acesso aos produtos e serviços através da própria empresa e de seus parceiros comerciais.

Em relação às estratégias empreendidas para a BoP no setor imobiliário, verificou-se que, das estratégias presentes na fundamentação teórica deste estudo, 18 delas foram executadas pelas empresas selecionadas para a pesquisa. Dentre elas, podem-se destacar a orientação e assessoria gerencial; a avaliação de risco e aprovação de crédito simplificado; o aproveitamento de políticas públicas; e o uso de internet.

A estratégia de orientação e assessoria gerencial apresentou-se como uma aliada para ajudar o cliente a não ficar inadimplente. Isto é muito importante não só para o cliente e a construtora, mas principalmente para as instituições financeiras que promovem a liberação de crédito, considerando que um alto número de inadimplentes pode gerar mais dificuldades para a liberação de crédito de novos clientes. Nessa perspectiva, a estratégia de avaliação de risco e aprovação de crédito simplificado assume importância, na medida em que a construtora necessita flexibilizar a forma de pagamento do valor de entrada do imóvel para viabilizar a sua venda.

A estratégia de aproveitar políticas públicas, por sua vez, tem um forte impacto para o desenvolvimento dos negócios da cadeia do setor imobiliário voltado para as pessoas da BoP no Brasil, pois o Governo Federal, por meio do PMCMV, tem subsidiado o financiamento dos imóveis com juros diferenciados dos praticados no mercado financeiro tradicional. Já a estratégia relacionada ao uso de internet tem sido uma ferramenta bastante utilizada, seja pelas empresas para o alcance de pessoas, seja pelos clientes para a busca de mais informações sobre os bens que pretendem adquirir.

Os resultados deste estudo contribuem para ampliar o conhecimento sobre a temática proposta, considerando que, apesar da amplitude do mercado da BoP no contexto brasileiro e da importância do setor imobiliário como gerador de empregos e renda, há escassez de estudos sobre como empresas desse setor estão organizadas para atender a esse público. Além disso, as evidências das ações estratégicas e das características da infraestrutura comercial necessárias para o atendimento dos consumidores da baixa renda podem servir de referência para empresas que almejem servir a este mercado.

O presente trabalho foi realizado no setor imobiliário da cidade de João Pessoa, capital do estado da Paraíba. Logo, sugere-se o empreendimento de pesquisas em outras cidades e regiões com o intuito de identificar e comparar ações estratégicas em diferentes mercados. Ademais, recomendam-se novos estudos quantitativos que contemplem um número significativo de empresas do setor imobiliário, de modo a melhor compreender os elementos que compõem a infraestrutura comercial para o atendimento a consumidores da BoP. 


\section{REFERÊNCIAS}

Araújo, C. M., \& Diniz, A. C. A. (2014). "Programa Minha Casa, Minha Vida" em Campina Grande PB: habitação para quem? Revista Movimentos Sociais e Dinâmicas Espaciais (Recife), 3(2), 281298.

Arnold, D. G., \& Valentin, A. (2013). Corporate social responsibility at the base of the pyramid. Journal of Business Research, 66(10), 1904-1914.

Bardin, L. (1977). Análise de conteúdo. São Paulo: Edições 70.

Barki, E., Botelho, D., \& Parente, J. (2013). Varejo: desafios e oportunidades em mercados emergentes. Revista de Administração de Empresas (São Paulo), 53(6), 534-538.

Brasil. (2016). Minha Casa Minha Vida entregou 2,4 milhões de moradias. Recuperado em 26 março, 2018,

http://www.brasil.gov.br/infraestrutura/2015/09/mi nha-casa-minha-vida-entregou-2-4-milhoes-demoradias

Castelo, A. M., \& Dias, E. C. (2013). Os desafios do Minha Casa Minha Vida na visão dos empresários. Revista Conjuntura da Construção, 11(2), 4-7.

Caixa Econômica Federal. (2017). Minha Casa Minha Vida 2017: entenda o que muda no programa. Recuperado de http://www20.caixa.gov.br/Paginas/Noticias/Notici a/Default.aspx?newsID $=4550$

Costa, Leonardo Barboza da. (2013). Estruturação da cidade de Campina Grande: as estratégias e intencionalidade do mercado imobiliário. Dissertação de mestrado, Universidade Federal da Paraíba, João Pessoa, PB, Brasil.

Federação das Indústrias do Estado de São Paulo. (2016). Levantamento inédito mostra déficit de 6,2 milhões de moradias no Brasil. Recuperado em 24 maio, 2016, de http://www.fiesp.com.br/observatoriodaconstrucao/ noticias/levantamento-inedito-mostra-deficit-de-62milhoes-de-moradias-no-brasil/

Filardi, F., \& Fischmann, A. (2015). Estratégias de empresas para a base da pirâmide. São Paulo: Atlas.

Fundação João Pinheiro. (2016). Déficit habitacional no Brasil. Recuperado em 26 março, 2018, de http://www.fjp.mg.gov.br/index.php/produtos-eservicos1/2742-deficit-habitacional-no-brasil-3
Gonçalves Junior, C. A., Dutra, R. L., Lopes, R. L., \& Rodrigues, R. L. (2014). O impacto do Programa Minha Casa, Minha Vida na economia brasileira: uma análise de insumo-produto. Ambiente Construído, 14(1), 177-189.

Guedes, A. A., De Araújo, D. L. A., \& Ornellas, R. S. (2012). Capacidades dinâmicas e vantagens competitivas: um estudo em uma construtora com foco no mercado de baixa renda. Anais do Simpósio de Administração da Produção, Logística $e$ Operações Internacionais. São Paulo, SP, Brasil, 15.

Hemais, M. W., Casotti, L. M., \& Rocha, E. P. G. (Abr. 2013). Hedonismo e moralismo: consumo na base da pirâmide. Revista de Administração de Empresas (São Paulo), 53(2), 199-207.

Hirata, F. (2009). "Minha Casa, Minha Vida": Política habitacional e de geração de emprego ou aprofundamento da segregação urbana?. Revista Aurora, 2(2).

Hofling, E. M. (2001, Nov.). Estado e políticas (públicas) sociais. Caderno Cedes (Campinas), 21(55), 30-41.

Instituto Brasileiro de Geografia e Estatística. (2013). Censo demográfico 2010: aglomerados subnormais, informações territoriais. Rio de Janeiro.

Jaiswal, A. (2008). Fortune at the bottom of the pyramid: an alternative perspective. Ahmedabad: Indian Institute of Management.

Karnani, A. (2007). The mirage of marketing to the bottom of the pyramid: how the private sector can help alleviate poverty. California Management Review, 49(4), 90-111.

Karnani, A. (2009). The bottom of the pyramid strategy for reducing poverty: a failed promise. DESA working paper n. 80, New York: United Nations Department of Economic and Social Affair, 1-14.

Landrum, N. (2007). Advancing the 'base' of the pyramid debate. Strategic Management Review, 1(1), 1-12.

London, T. A. (2007). Base-of-the-pyramid perspective on poverty alleviation. Working Paper. School of Business at the University of Michigan.

Luz, J. R. M. (2011). Gestão estratégica baseada na qualidade e custos da qualidade: um estudo no setor de construção civil da cidade de Campina 
Grande-PB. Dissertação de mestrado, Universidade Federal da Paraíba, João Pessoa, PB, Brasil.

Maciel, C. (2013). Redes sociais são usadas em proporções similares por todas as classes, segundo pesquisa. Recuperado em 26 março, 2018, de http://www.ebc.com.br/noticias/brasil/2013/06/rede s-sociais-sao-usadas-em-proporcoes-similares-portodas-as-classes

Medeiros, F. B. (2007). Análise da adequação dos programas de financiamento habitacional para atender as necessidades de aquisição de moradias adequadas da população de baixa renda no Brasil. Dissertação de mestrado, Universidade de São Paulo, São Paulo, SP, Brasil.

Melo, M. D. (2016). O acesso à habitação no Brasil em tempos de capitalismo financeirizado - uma análise do Programa Minha Casa, Minha Vida. Dissertação de mestrado, Universidade de Brasília, Brasília, DF, Brasil.

Ministério das Cidades (2016). Programa Minha Casa, Minha Vida. Recuperado em 23 maio, 2016, de http://www.cidades.gov.br/habitacaocidades/programa-minha-casa-minha-vida-pmcmv

Moura, E. O., Machado, A. G. C., \& Bispo, M. S. (2015). O microcrédito como fomentador de uma infraestrutura comercial voltada para a base da pirâmide: o caso do programa empreender bananeiras. Gestão \& Conexões, 4(2), 84-104.

Nogami, V. K. C., \& Pacagnan, M. N. (2011). Consumo da base da pirâmide: uma análise bibliométrica do estado da arte na produção acadêmica no Brasil. Anais do Encontro Nacional da Associação de Pós-Graduação e Pesquisa em Administração, Rio de Janeiro, RJ, Brasil, 35.

Oliveira, G. M., \& Machado, A. G. C. (2016). Inovação em serviços para a base da pirâmide no setor varejista. Revista Ciências Administrativas, 22(2), 423-450.

Parente, J., Limeira, T. M. V., \& Barki, E. (2009). Varejo para a baixa renda. Porto Alegre: Bookman.

Passos, C. A. (2013). A eficiência e a estratégia das empresas que atuam no mercado de bens populares no Brasil: um estudo de caso sobre o setor de móveis. Dissertação de mestrado, Faculdade de
Economia, Administração e Contabilidade, Universidade de São Paulo, São Paulo, SP, Brasil.

Prahalad, C. K. (2010). A riqueza na base da pirâmide: como erradicar a pobreza com lucro. Porto Alegre: Bookman.

Prahalad, C. K., \& Hart, S. L. (2002). The fortune at the bottom of the pyramid. Strategic Business, 26, $1-14$.

Ramos, J. S., \& Noia, A. C. (2016). A construção de políticas públicas em habitação e o enfrentamento do déficit habitacional no Brasil: uma análise do Programa Minha Casa Minha Vida. Desenvolvimento em Questão, 14(33), 65-105.

Rocha, A., \& Silva, J. F. (2008, Dez.). Inclusão social e marketing na base da pirâmide: uma agenda de pesquisa. Revista de Administração de Empresas (São Paulo), 7(2).

Rodrigues, A., Rojo, C. A., \& Bertolini, G. R. F. (2013, Jun.). Formulação de estratégias competitivas por meio de análise de cenários na construção civil. Production (São Paulo), 23(2), 269-282.

Schreiber, D. (2013). Estratégia como prática no segmento de construção civil. Revista Brasileira de Gestão e Inovação, 1(1).

Simanis, E., \& Hart, S. (2008). The base of the pyramid protocol: toward next generation BoP strategy. Cornell University, 2, 1-57.

Virgilio, L. M. (2010). Financiamento para habitações populares no Brasil e no México: uma análise comparada. Dissertação de mestrado, Escola Politécnica, Universidade de São Paulo, São Paulo, SP, Brasil.

Wright, J. T. C., \& Spers, R. G. (2011). Mercado popular no Brasil - abordagens para geração de negócios e casos de sucesso. São Paulo: Blucher.

Yamashita, A. P., \& Rego, R. A. (2009). Bancos e microfinanças: lucro e inclusão social no atendimento do mercado da base da pirâmide. Interface - Revista do Centro de Ciências Sociais Aplicadas, 6(1), 100-113.

Zilber, S. N., \& Silva, F. L. (2010, Set.). Estratégias das grandes empresas para o mercado brasileiro da base da pirâmide. Economia Global e Gestão (Lisboa), 15(2), 25-50. 